\title{
Sub or snub: Is subvalvular repair worthwhile in severe ischemic mitral regurgitation?
}

\author{
Tomasz A. Timek, MD, PhD
}

\footnotetext{
From the Division of Cardiothoracic Surgery, Michigan State University College of Human Medicine, Grand Rapids, Mich.

Disclosures: Author has nothing to disclose with regard to commercial support.

Received for publication Oct 19, 2016; accepted for publication Oct 20, 2016; available ahead of print Nov 30, 2016.

Address for reprints: Tomasz A. Timek, MD, PhD, Division of Cardiothoracic Surgery, Michigan State University College of Human Medicine, Spectrum Health, 100 Michigan Ave NE, Grand Rapids, MI 94305-5407 (E-mail: tomasz.timek@spectrumhealth.org).

J Thorac Cardiovasc Surg 2017;153:296-7

$0022-5223 / \$ 36.00$

Copyright (c) 2016 by The American Association for Thoracic Surgery

http://dx.doi.org/10.1016/j.jtcvs.2016.10.069
}

Ischemic mitral regurgitation continues to frustrate and challenge surgeons and cardiologists alike. In this issue of the Journal, Nappi and colleagues ${ }^{1}$ present a subanalysis of a recently published randomized trial ${ }^{2}$ of surgical treatment of severe ischemic mitral regurgitation with undersized ring annuloplasty versus annuloplasty supplemented with subvalvular papillary muscle approximation. Nappi and colleagues ${ }^{1}$ analyzed preoperative echocardiographic characteristics to define better the added benefit of a subvalvular procedure in improving left ventricular remodeling and reducing recurrent insufficiency at 5-year follow-up. The study found that left ventricular remodeling was enhanced and rate of recurrent mitral regurgitation reduced when papillary muscle approximation was added to undersized ring annuloplasty, particularly in the setting of asymmetric leaflet tethering or inferior wall dyskinesia.

Nappi and colleagues ${ }^{1}$ are to be congratulated for carrying out a pioneering randomized trial that, although it does not solve the intricate puzzle of ischemic mitral regurgitation, identifies more targeted therapy for patients with defined clinical features. Failure of undersized annuloplasty to correct ischemic mitral regurgitation reliably has been linked to continued left ventricular remodeling and has generated interest in subvalvular interventions to yield a more durable and complete valve repair. Experimental and clinical interventions have been developed to address the subannular pathophysiology of ischemic mitral regurgitation, including device-driven inferior wall displacement, ${ }^{3}$ direct internal $^{4}$ or external ${ }^{5}$ papillary tip fixation, secondary chordal cutting, ${ }^{6}$ and papillary muscle imbrincation ${ }^{7}$ and sling approximation. ${ }^{8}$ The study of Nappi and colleagues ${ }^{1}$ continues this important line of investigation. The presented results, however, will need validation in a more extensive clinical experience, because the number of patients available for evaluation at 5 years, especially in subgroup analysis, was quite low, making concrete conclusion difficult. Ischemic mitral regurgitation encompasses a heterogeneous patient population, and caution should be exercised in enthusiasm.

\section{References}

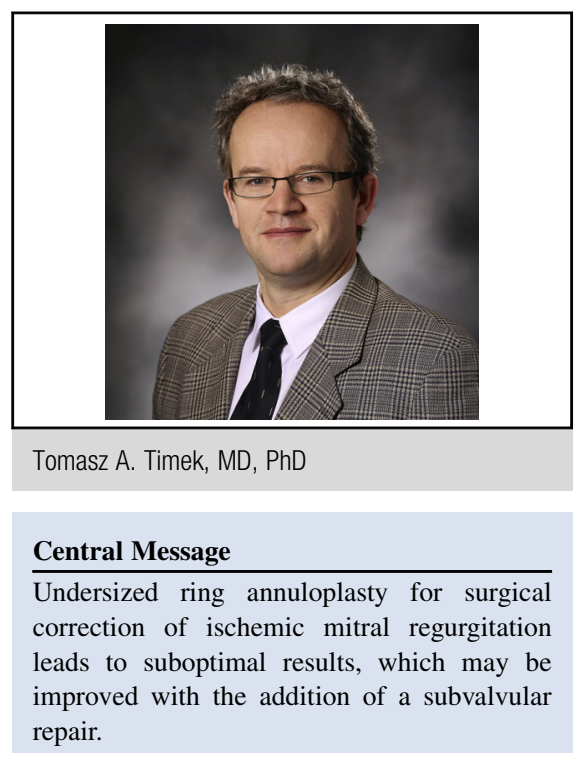

See Article page 286

generalizing these results to avoid surgical errors of the past. Because asymmetric tethering is usually related to dyskinesia of the inferior left ventricular wall, which subtends the posterior papillary muscle, these variables are essentially surrogates and study conclusions may be overstated. The rate of recurrent moderate-to-severe mitral regurgitation at 5 years was still $27 \%$ in the subvalvular repair group, and this procedure would therefore not be expected to be superior to mitral valve replacement, which is technically less challenging, more reliable, and more reproducible. Lack of mortality benefit further tempers surgical

The surgical approach utilized by Nappi and colleagues represents another evolutionary step toward directly treating the "ventricular" disease that is ischemic mitral regurgitation. Nappi and colleagues ${ }^{1}$ have demonstrated that supplementing standard undersized ring annuloplasty with a subvalvular repair may be beneficial; however, learning when and if to "sub" will require further work.

1. Nappi F, Spadaccio C, Nenna A, Lusini M, Fraldi M, Acar C, et al. Is subvalvular repair worthwhile in severe ischemic mitral regurgitation? Subanalysis of the papillary muscle approximation trial. J Thorac Cardiovasc Surg. 2017; 153:286-95.e2. 2. Nappi F, Lusini M, Spadaccio C, Nenna A, Covino E, Acar C, et al. Papillary muscle approximation versus restrictive annuloplasty alone for severe ischemic mitral regurgitation. J Am Coll Cardiol. 2016;67:2334-46. 
3. Hung J, Guerrero JL, Handschumacher MD, Supple G, Sullivan S, Levine RA. Reverse ventricular remodeling reduces ischemic mitral regurgitation: echo-guided device application in the beating heart. Circulation. 2002; 106:2594-600.

4. Kron IL, Green GR, Cope JT. Surgical relocation of the posterior papillary muscle in chronic ischemic mitral regurgitation. Ann Thorac Surg. 2002;74:600-1.

5. Langer F, Kunihara T, Hell K, Schramm R, Schmidt KI, Aicher D, et al. RING+STRING: successful repair technique for ischemic mitral regurgitation with severe leaflet tethering. Circulation. 2009;120(11 Suppl):S85-91.
6. Borger MA, Alam A, Fazel S, Fazel S, Maganti M, Armstrong S, et al. Initial results of chordal-cutting operation for ischemic mitral regurgitation. J Thorac Cardiovasc Surg. 2007;133:1483-92.

7. Shudo Y, Matsumiya G, Sakaguchi T, Miyagawa S, Yoshikawa Y, Yamauchi $\mathrm{T}$, et al. Assessment of changes in mitral valve configuration with multidetector computed tomography: impact of papillary muscle imbrication and ring annuloplasty. Circulation. 2010;122(11 Suppl): S29-36.

8. Hvass U, Joudinaud T. The papillary muscle sling for ischemic mitral regurgitation. J Thorac Cardiovasc Surg. 2010;139:418-23. 